
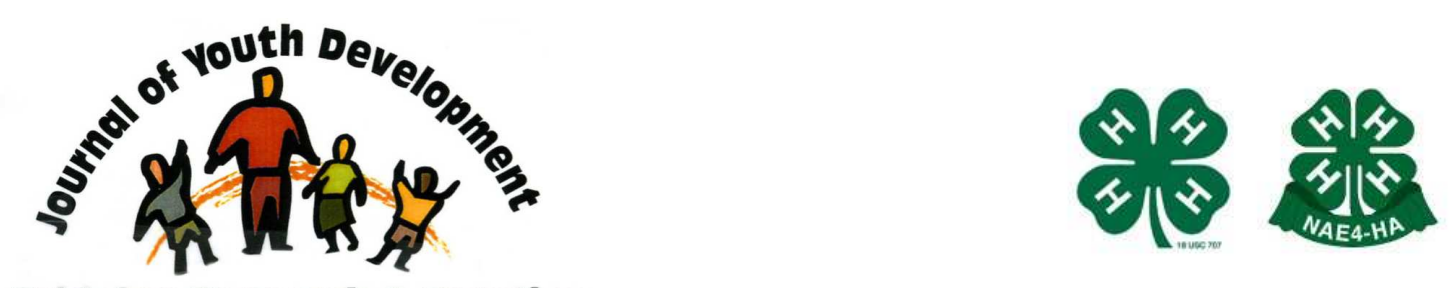

Bridging Research \& Practice

\title{
A Qualitative Investigation of Californian Youth Interests in the Outdoors
}

\author{
Marni Goldenberg \\ Recreation, Parks, \& Tourism Administration Department \\ California Polytechnic State University \\ San Luis Obispo, CA \\ mgoldenb@calpoly.edu
}

Katherine Wassenberg

Recreation, Parks \& Tourism Administration Department

California Polytechnic State University

San Luis Obispo, CA

kewassenberg@gmail.com

Jerusha Greenwood

Recreation, Parks \& Tourism Administration Department California Polytechnic State University

San Luis Obispo, CA

jbgreenw@calpoly.edu

William Hendricks

Recreation, Parks \& Tourism Administration Department California Polytechnic State University

San Luis Obispo, CA

whendric@calpoly.edu

Jeff Jacobs

Recreation, Parks \& Tourism Administration Department

California Polytechnic State University

San Luis Obispo, CA

jacobs@calpoly.edu

Jason Cummings

Recreation, Parks \& Tourism Administration Department

California Polytechnic State University

San Luis Obispo, CA

jpc2178@yahoo.com 


\title{
JOURNAL OF YOUTH DEVELOPMENT \\ bridging research and practice

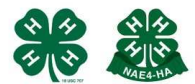

Bridging Research \& Practice

Volume 5, Number 1, Spring 2010

Article 100501FA003

\section{A Qualitative Investigation of Californian Youth Interests in the Outdoors}

Marni Goldenberg, Katherine Wassenberg, Jerusha Greenwood, William Hendricks, Jeff Jacobs and Jason Cummings

California Polytechnic State University

\begin{abstract}
Prior research has found connections between youth participation in recreational activities and academic achievement, civic involvement, and improved health. To investigate California youth outdoor recreation attitudes, behaviors, and constraints, eight focus groups were conducted with community recreation center youth participants. Youth answered 10 questions about their experiences, attitudes, and perceptions of outdoor recreation. Data were analyzed using grounded theory. Three to seven axial codes were identified for each question. Results showed that youth want to have more access to outdoor recreational activities. However, there are frequently considerable constraints for the youth to overcome including draws of technology, family obligations, and laziness. Safety was a recurring concern among participants. Understanding youth attitudes and perceptions allows managers to meet youth needs, program for youth interests, provides a strong foundation for marketing and as a rational for funding grants.
\end{abstract}

\section{Introduction}

Investigating California youth outdoor recreation attitudes, behaviors, and constraints is a priority of the California Department of Parks and Recreation. Prior research has revealed connections between youth participation in recreational activities and academic achievement, civic involvement, and improved health (Larson, 2000; Peck, Roeser, Zarrett, \& Eccles, 2008; Zaff, Moore, Papillo, \& Williams, 2003). With more than 14 million K-12 students having limited adult supervision after school, and most delinquent adolescent behavior (including sexual activity, drug and alcohol use, and violence) occurring between 2:00-8:00 p.m., it is important to assist youth, especially unsupervised youth, in finding and engaging in constructive recreational activities (Gootman, 2000; Libby, 2007). A 4-H study demonstrated the need to 
provide youth with a selection of recreational opportunities and the ability to choose activities in which to participate (Theokas, Lerner, Phelps, \& Lerner, 2006). An understanding of perceived constraints to participation provides the opportunity to increase constraint negotiation and allows for more frequent and significant participation (Schneider \& Wilhelm Stanis, 2007).

Understanding that youth themselves can provide the greatest insight into their interests and perceived constraints, youth focus groups were conducted as a component of The Public Opinions and Attitudes on Outdoor Recreation survey, which is conducted every five years by the California Department of Parks and Recreation as an element of the California Outdoor Recreation Plan (California State Parks, 2009). This study aims to determine interest levels and frequency of participation among California youth in outdoor recreation activities, as well as their negotiation of perceived participation constraints.

\section{Methods}

\section{Study Locale}

Eight focus groups were conducted in large cities within four geographical regions of California, including San Diego, Modesto, Livermore, and the Los Angeles Metro Area. Residents of these regions represent $90 \%$ of the state's population.

A research assistant contacted community recreation centers in each of the cities by telephone and email to determine their interest in participating in the study. Focus groups in San Diego and Los Angeles occurred in September of 2007. Those in Modesto and Livermore occurred in November of 2007. In April 2008, focus groups were repeated in Los Angeles due to a technological failure to record the interviews when the audio recorder could not pick up the voices because people were seated too far away.

\section{Description of Subjects}

The sample for the study was limited to community recreation center youth participants, aged 10-17, from the four geographical regions stated above. Participants were asked to participate in the study. Seventy-two California youths participated in these focus group sessions.

Youth in each geographical region were divided into two groups based on age (10-13 and 1417). Participating recreation centers disseminated parental permission and human subject forms to the parents/guardians of their youth members prior to the focus groups. Youth who returned permission forms and were available at the time of the focus group were able to participate.

\section{Description of Instrument}

Researchers developed the interview script for the focus groups based on a similar format to the 2008 Oregon Statewide Comprehensive Outdoor Recreation Plan (Burn, Autry, \& Graefe, 2007). In order to verify the relevance of the script to its target population of California youth, an expert panel was consulted to review the script. A pilot test was conducted with a youth group in Atascadero, CA to test the script, the audio recording of the youths' comments, and the overall format of the focus groups. No changes to the interview script resulted from the pilot test.

The focus group interview script was composed of three warm-up questions and 10 focused questions. The warm-up questions asked participants about swimming in the ocean, spending a night in a tent, and their favorite month. The purpose of the warm-up questions was to 
encourage the youth to actively participate in the focus group. The 10 focused questions included:

1. When you think about the outdoors, what kinds of things pop into your mind?

2. What activities do you do in the outdoors?

3. How much time do you spend outdoors? How important is it for you to increase your time spent outdoors in the future?

4. Are there any outdoor activities that would you like to participate in, that you haven't tried yet? What are these activities?

5. What do you enjoy most about being outdoors? Why? What do you like about doing these activities outdoors?

6. What don't you enjoy about outdoor activities? Is there anything you don't like about the outdoors or doing things outdoors?

7. What keeps you from participating in outdoor activities? What keeps you from doing more in the outdoors (or being outside more)?

8. There are people whose job is to manage parks. What can they do to get kids interested in doing things outdoors?

9. Have you participated in an outdoor activity because someone brought you to that location or taught you that activity? Was it your parents, school, or organizations that you belong to?

10. Do you recreate in the same places that your parents visited as kids? What do your parents say about this place?

\section{Study Procedures}

The researchers used audio to record the eight focus groups; however, only seven of those recordings were useable and transcribed by a research assistant. Field notes were used to analyze the eighth session. During each focus group, one or two researchers conducted the interview while a third researcher recorded the session and took notes. A research assistant listened to the audio recordings and created a transcript for each of the focus groups.

\section{Data Analysis}

A researcher and research assistant analyzed the transcribed results through categorization of participant responses into axial codes or thematic categories. Using grounded theory techniques, each focus group session was reviewed by searching for thematic categories and subcategories within participant responses, which were then developed into major themes (axial codes) that described the data (Silverman, 2004; Strauss \& Corbin, 1990).

The axial codes identified in this data set included:

- Activities

- Amenities

- Community/People

- Environment

- Environment Base

- Exercise-Oriented

- Location

- Mechanized 
- Outdoor Recreational

- Passive

- Personal

- Physical

- Team Sports

- Social

- Structure

These axial codes were selected based on previous leisure research (Iso-Ahola, Jackson \& Dunn, 1994; Jackson, 1987; Jackson, 1994) that identified categories of leisure and outdoor recreation activities.

The researcher and research assistant worked together to find themes for one transcription by reading a participant's statement and answering the question "What is being referred to here?" After one focus group session was coded, the researcher and research assistant then separately coded the remaining seven sessions. Inter-rater reliability was $90 \%$ between their coding. Discrepancies were resolved by returning to the original transcriptions. A third researcher reviewed the three to seven axial codes (major themes) that emerged for each question and was in agreement with the coded data.

\section{Results}

\section{Study Participants}

Demographic information was self-reported by subjects during the focus group sessions, as subjects raised their hand to indicate their race. Most respondents were Hispanic $(n=25)$, Caucasian $(n=21)$, or African American $(n=16)$. Other racial groups represented were Asian, Native American, and multiracial. Males $(n=38)$ and females $(n=34)$ were almost equally represented. Of the 72 participants, 32 were 10-13 years old, and 40 were $14-17$ years old.

\section{Focused Questions}

In analyzing the focus group data, between three and seven axial codes (major themes) were identified for each question. These three axial codes were each appeared in four questions: Environment, Social, and Other. Two axial codes appeared in three questions: Personal and Physical. Seven axial codes were each identified in two questions: Activities, Amenities, Exercise-Oriented, Location, Mechanized, Outdoor Recreational, and Team Sports. The following four axial codes were identified for a single question: Community/People, Environment Base, Passive, and Structure.

\section{Question One}

The first interview question asked subjects "When you think about the outdoors, what kinds of things pop into your mind?" Responses from the first interview question fit into four axial codes: Environment, Activities, Community/People, and Location. Within the Environment category, participants frequently mentioned the animals, water (such as lakes, rivers, and the ocean), and trees. Within the Activities category, participants frequently mentioned camping/tents, skateboarding/skate parks, biking, and walking (either with or without a dog). In the Community/People category, participants most often mentioned people (such as hippies or mountain men), happiness/fun, and community/neighborhood/ houses/schools. Within the Locations category, participants mentioned locations such as Santa Cruz, Costa Rica, and Renaissance Fair. 
One high school subject from Livermore responded that she thinks about: "Wilderness compared to, like, industrialization. It's just the opposite of that whole idea." A middle school student from LA stated, "I think about the trees and the plants and the environment." When asked what it was about the environment, this subject responded "like how it should be clean."

\section{Question Two}

The second question asked subjects what activities they do in the outdoors. Participants referred to six axial codes: Outdoor Recreational, Exercise-Oriented, Team Sports, Mechanized, Passive, and Other. Within the Outdoor Recreational category, participants most often mentioned skateboarding, camping, and hunting. Within the Exercise-Oriented category, participants most often mentioned swimming and hiking. Within the Team Sports category, participants most often mentioned football, soccer, basketball, and baseball. Within the Mechanized category, participants most frequently mentioned biking, but three/four wheeling and motorcycling were also mentioned.

A high school student from Livermore explained: "I mostly surf, pretty much the only outdoor sport I do. I'm not much of a sports kind of person." While another student in the same focus group explained "just sit outside."

\section{Question Three}

Subjects were asked "How much time do you spend in the outdoors?" A middle school student from Lakeside answered: "Most of my day. As soon as I get home, then I go outside and ride my bike and stuff." A middle school student from Los Angeles stated the opposite: "I want to stay indoors because I want to play my Xbox 360."

Also, subjects were asked "How important is it for you to increase your time spent outdoors in the future?" A middle school female from Modesto said: "Well, it depends...if it's really hot outside than decrease, but if it's just like the perfect weather, increase." "I say both [indoors and outdoors] because when you're indoors you can still play but not like how you play outdoors and I say outdoors because you're being active and not just sitting around watching tv or playing video games" stated a middle school student from Los Angeles.

Subjects reported spending a median of three to four hours in the outdoors on an average day and $81 \%$ of participants indicated that they would like to increase the number of hours that they spend outside.

\section{Question Four}

In response to "Are there are any outdoor activities that you would like to participate in, that you haven't tried yet? What are these activities?" Responses from all subjects included references to five axial codes: Exercise-Oriented, Outdoor Recreational, Team Sports, Mechanized, and Other. Outdoor Recreational and Mechanized were most frequently cited. Within the Outdoor Recreational category, participants often mentioned mountain/rock climbing, snowboarding, kayaking, skiing, and scuba diving. Within the Mechanized category, participants most frequently mentioned skydiving and motorized/non-motorized forms of biking. Team Sports included football, ice hockey, tennis, basketball, and lacrosse. Other activities included traveling more and bungee jumping. 
One middle school student from Lakeside said "I want to go camping. The only thing that worries me is that we have coyotes where we go." Another middle school subject from LA said "I say football because I've seen people play it but I've never."

\section{Question Five}

Subjects were asked "What do you like most about being outdoors? Why? What do you like about doing these activities outdoors?" Five axial codes were found in response to this question, including: Environment, Physical, Personal, Social, and Other. Personal was the most frequently cited, with participants often mentioning fun/enjoyment, experiencing new places/things, and forget about stress/peaceful/relaxing. Within the Environment category, participants most frequently mention weather. In the social category, participants most frequently mentioned friends.

One high school student from LA said, "It's better than being in the house. I'm not a coach potato. I want to have fun, go places. Being in a house is just like being restricted to certain things you can do." A middle school male student from Modesto explained that "I like to let my anger out on the ball. I like being away from technology." A middle school student from Lakeside stated "I like playing sports because I get to hang out with my friends and I also get to sing songs." Several youth referred to being with friends as an important component to being outside.

\section{Question Six}

The sixth focus group question addressed "What don't you enjoy about outdoor activities? Is there anything you don't like about the outdoors or doing things outdoors?" Subjects referred to four axial codes in their responses: Environment, Physical, Personal, and Social. Environment was the most frequently cited, with the majority of participants mentioning weather. In the Personal category, participants mentioned safety.

A middle school student from Lakeside said, "I hate it when it's too cold because we don't get grass and we can't really play football, stuff like that." Another from Livermore explained that "Generally, I associate outdoor activities with exercise and sweating stuff, and I don't like that, exercising and moving, I'm not a fan of that." A high school student from LA stated "I don't like losing, I like to win" in reference to being successful at an outdoor activity.

\section{Question Seven}

When asked "What keeps you from participating in outdoor activities? What keeps you from doing more in the outdoors (or being outside more)?" five axial codes emerged, including: Environment, Physical, Personal, Social, and Amenities. Social and Amenities were most frequently cited. Within the Social category, participants most often mentioned family influence and school/homework. Within the Amenities category, participants most frequently mentioned technology/electronics. Physical included health and injuries, and personal included constraints such as time schedule and laziness/effort.

One middle school student from Lakeside said "My mom's been making me stay inside because of studying and everything." A middle school male student from Modesto explained "Only when it's day. Because when it's dark, it's creepy, well, like, you can't see and you want to be able to see." A high school student from LA stated "we can play basketball because we have a court, but other sports you can't play baseball because we don't have a baseball field, football you run into rocks, can't play soccer because you could hit someone's car in the parking lot." 


\section{Question Eight}

Subjects were told "There are people whose job is to manage parks. What can they do to get kids interested in doing things outdoors?" In their responses, subjects mentioned three axial codes: Social, Amenities, and Other. Amenities was most frequently cited including wanting more courts, fields, and parks, as well as sports equipment, skate parks, and game centers. Within the Social category, participants most frequently mentioned safety, such as no drinking, no smoking, no drugs, no homeless people, more lighting, park security, and also referred to having clean bathrooms.

A high school student from Modesto said "Making better lighting at night, it's pitch black." One Livermore high school student suggested that "teenagers [should] have more of a voice, like, if they don't like what's being done, they can change it." A high school youth from Modesto wants the managers of parks to provide "more family environment, you can't take kids to a park when they're like drinking or if it's like [t]here for an example, it's like for me I would be afraid to walk by this park alone."

\section{Question Nine}

The final two focused interview questions asked about subjects' outdoor influences. Subjects were asked "Have you participated in an outdoor activity because someone brought you to that location or taught you that activity? Was it your parents, school, organizations that you belong to?" Subjects also mentioned their dad, mom, sibling, family, friends, club/camp/center, and school/teacher. Of 91 responses (some students responded more than once), 40 (44\%) referred to a family member, 31 (34\%) of responses referred to a club/camp/center, $12(13 \%)$ referred to a friend, and $8(9 \%)$ referred to a school/teacher.

One middle school male Modesto student recalled that "One time, I went to this camp for school and we went there for three days of the week and we got to take hikes up this huge mountain and we got to, like, rock climb." A student from LA High explained "My sister taught me how to play freeze tag in the park."

\section{Question Ten}

The final question asked subjects "Do you recreate in the same places that your parents visited as kids? What do your parents say about this place?" In their responses, subjects referred to four axial codes: Location, Structure, Environment Base, and Activity. Environment Base and Location were most frequently mentioned. Within the Environment Base category, participants most often mentioned visiting the same beach their parents had visited.

\section{Limitations}

In analyzing these results, it is necessary to consider the strengths and limitations of the methods employed. By their nature, focus groups provide subjects with an interactive and open forum to express opinions and experiences but these focus groups were also limited to the information that youth were willing to reveal. Youth may chose not to share personal or embarrassing perceptions and experiences in a group setting. They may also not reveal their participation in illicit behaviors. Participation in the study was limited to community recreation center youth participants living in four urban areas of the state of California. The perspectives of youth living in rural and other urban areas, as well as those of youth who do not participate in their community recreation centers were not represented. Their experiences and perceptions of the outdoors could be wildly different from those of the youth represented in this study. 


\section{Discussion}

Outdoor recreation researchers have concluded that communities need to create programs that meet youth needs, both in terms of variety and reliability (e.g. Theokas, Lerner, Phelps, \& Lerner, 2006; Witt \& Caldwell, 2005). The results from this research show that a large majority of youth want to have more access to outdoor recreational activities. Burns, Autry, and Graefe (2007) state that "Connecting youth to the outdoors and to nature is a critical need within our society and it is critical for positive youth development" (p. 9).

The State of California has already made significant steps to empower youth in building a connection to the outdoors, especially through the development of the California Children's Outdoor Bill of Rights (COBR), which strives to offer children the opportunity to participate in 10 specific outdoor activities before the age of 14 (California Roundtable on Recreation, Parks and Tourism, 2004). In this study, key themes emerged relevant to 9 of the 10 COBR activities: Splash in the Water, Play in a Safe Environment, Camp under the Stars, Explore Nature, Learn to Swim, Play on a Team, Follow a Trail, Catch a Fish, and Celebrate Your Heritage. No relevant themes surfaced on the final activity, Discover California's Past.

Although the findings show that California youth want to engage in outdoor recreational activities, and often do so, there are frequently considerable constraints for the youth to overcome. For example, park safety, time, and the draws of technology keep kids inside and away from natural areas. Several youth mention a lack of community facilities and their desire to have greater availability of swimming pools, hiking trails, mountain biking/motocross trails with curves and jumps in their communities and through their recreation centers. Participants frequently mention family obligations (e.g. holiday celebrations, babysitting siblings, chores) as a leisure constraint. Some feel excluded from team sports because of their skill level, the skill level of other players, or the competitive nature of the sport.

Safety was a recurring theme among participants and perhaps a constraint in need of further investigation. The subjects express concerns including: the homeless, gangs, older youths, needles in play areas, drugs in public bathrooms, and lack of lighting at night. Other leisure constraints include parents not allowing youths to play outside because of a lack of safety and supervision. Some youths recommend having security guards or police stationed at parks as leisure constraint negotiations. Prior youth research exemplifies the importance of understanding how negative experiences can interfere with future participation (Dworkin \& Larson, 2006). Future research should focus on how youths' perceptions of safety, fears/concerns, and prior negative experiences affect their interest and desire for future outdoor recreation participation.

Additional research is needed to understand the outdoor recreation interests and constraints of a greater portion of California youth, specifically rural youths and youth that do not participate in community recreation centers.

\section{Implications for Practice}

Management of community outdoor recreational facilities can assist youth in their pursuit of participation in outdoor recreation through assessment of their capacity to provide desired facilities and recreational opportunities. Understanding youth attitudes and perceptions allows managers to meet youth needs, program for youth interests, and provides a strong foundation for marketing. Youth expressed desire for greater amenities in their communities, frequently mentioning more courts, fields, and parks, as well as sports equipment, skate parks, and game 
centers. Significant attention should be paid to youth concerns for safety in community areas through facility design, innovation, and instituting partnerships with local law enforcement agencies. For field practitioners seeking grant funding, this research may also serve as valuable rationale.

As participation in recreational activities has a positive impact on youth health concerns, understanding factors that effect youth participation is important. In additional to their desires for community resources, this research shows that as youth recreate with the people around them, adults have a strong influence on youth outdoor recreation behaviors. This influence extends to parents, siblings, extended family, education professionals, and youth organization.

\section{References}

Burns, R., Autry, C., \& Graefe, A. (2007). Youth focus group interviews: Oregon statewide comprehensive outdoor recreation plan. Retrieved August 11, 2009, from http://www.oregon.gov/OPRD/PLANS/SCORP.shtml

California Roundtable on Recreation, Parks and Tourism. (2004). California children's outdoor bill of rights. Sacramento, CA. Retrieved September 9, 2009, from http://www.calroundtable.org/files/cobr edit.pdf

California State Parks. (2009). Reference data: Survey on public opinions and attitudes on outdoor recreation in California 2007. Sacramento, CA.

Dworkin, J., \& Larson, R. (2006). Adolescents' negative experiences in organized youth activities. Journal of Youth Development, 1(3). Retrieved January 12, 2009, from http://www.youthdev.illinois.edu/Documents/DworkinLarson2006.pdf

Gootman, J.A. (Ed.). (2000). After-school programs to promote child and adolescent development: Summary of a workshop. Washington, DC: National Academy Press, Board on Children, Youth, and Families, Commission on Behavioral and Social Sciences and Education, Institute of Medicine, National Research Council.

Iso-Ahola, S.E., Jackson, E.L., \& Dunn, E. (1994). Starting, ceasing, and replacing leisure activities over the life-span. Journal of Leisure Research, 26(3), 227-249.

Jackson, E.L. (1987). Outdoor recreation participation and views on resource development and preservation. Leisure Sciences, 9(4), 235-250.

Jackson, E.L. (1994). Activity-specific constraints on leisure participation. Journal of Park and Recreation Administration, 12(2), 33-49.

Larson, R.W. (2000). Toward a psychology of positive youth development. American Psychologist, 55(1), 170-183.

Libby, B. (2007). Fourteen million kids, unsupervised: Can after-school programs help? Retrieved August 11, 2009, from http://www.edutopia.org/fourteen-million-kids-unsupervised 
Peck, S.C., Roeser, R.W., Zarrett, N., \& Eccles, J.S. (2008). Exploring the roles of extracurricular activity quantity and quality in the educational resilience of vulnerable adolescents: Variableand pattern-centered approaches. Journal of Social Issues 64(1), 135-156.

Schneider, I.E., \& Wilhelm Stanis, S.A. (2007). Coping: An alternative conceptualization for constraint negotiation and accommodation. Leisure Sciences, 29(4), 391-401.

Silverman, D. (Ed.). (2004). Qualitative research: Theory, method, and practice (2nd ed.). Thousand Oaks, CA: Sage.

Stauss, A., \& Corbin, J. (1990). Basics of qualitative research. Newbury Park, CA: Sage.

Theokas, C., Lerner, J.V., Phelps, E., \& Lerner, R.M. (2006). Cacophony and change in youth after school activities: Findings from the 4-H study of positive youth development. Journal of Youth Development, 1(1), Article 0601FA001. Retrieved January 12, 2009, from http://www.national4-hheadquarters.gov/library/Theokas JYD May06.pdf

Witt, P.A., \& Caldwell, L.L. (Eds.). (2005). Recreation and youth development. State College, PA: Venture Publishing

Zaff, J.F., Moore, K.A., Papillo A.R., \& Williams, S. (2003). Implications of extracurricular activity participation during adolescence on positive outcomes. Journal of Adolescent Research, 18(6), 599-630.

(C) Copyright of Journal of Youth Development $\sim$ Bridging Research and Practice. Content may not be copied or emailed to multiple sites or posted to a listserv without copyright holder's express written permission. However, users may print, download or email articles for individual use. 